\title{
Avaliação do Grau de Hidrólise e da Rotulagem de Suplementos Proteicos à Base de Whey Protein
}

\section{Evaluation of the Degree of Hydrolysis and the Labeling of Whey Protein-Based Supplements}

\author{
Leandro Marçal Duclou Soares; ; Mauro Ramalho Silva ${ }^{\mathrm{b}}$; Henrique de Oliveira Prata Mendonçac; Júlio Onésio Ferreira \\ Melo*d; Maria Aparecida Vieira Teixeira Garcia ${ }^{a}$; Raquel Linhares Bello de Araújo ${ }^{\text {e }}$ \\ ${ }^{a}$ Universidade Federal de Minas Gerais. MG, Brasil. \\ bUniversidade Federal de Minas Gerais, Programa de Pós-Graduação Stricto Sensu em Ciências de Alimentos. MG, Brasil. \\ 'Universidade Federal de São João Del-Rei. MG, Brasil. \\ 'Universidade Federal de São João Del-Rei, Programa de Pós-Graduação Stricto Sensu em Ciências de Alimentos. MG, Brasil. \\ eUniversidade Federal de Minas Gerais, Faculdade de Farmácia, Departamento de Alimentos. MG, Brasil. \\ *E-mail: onesiomelo@gmail.com
}

\begin{abstract}
Resumo
Em busca de um melhor rendimento esportivo e também na estética corporal, consumidores têm estimulado o crescimento do mercado dos suplementos alimentares, principalmente, os de fonte proteica na forma intacta e também hidrolisada. Em contrapartida, estudos têm demonstrado não conformidades nos requisitos regulamentados pela legislação vigente em relação à rotulagem destes produtos, fazendo das análises de qualidade um tema de extrema relevância. Desta forma, este estudo teve por objetivo analisar os suplementos proteicos do tipo whey protein em relação à presença de proteína intacta e ao grau de hidrólise, bem como a avaliação da adequação da sua rotulagem. Para isso, foram analisadas 9 marcas de suplementos proteicos do tipo whey protein disponíveis no mercado nacional. O teor proteico foi avaliado pelo método de Kjeldahl e o grau de hidrólise foi determinado por meio da relação entre o nitrogênio $\alpha$-aminado e o nitrogênio total. Para a verificação da adequação da rotulagem foi elaborado um check list de forma a atender a legislação vigente. Dentre as marcas avaliadas, observou-se que $88 \%$ delas apresentaram, no mínimo, um tipo de não conformidade com relação à rotulagem. Em relação ao teor proteico, uma marca apresentou valor abaixo $(-35,08 \%)$ da tolerância permitida pela legislação. Na verificação do grau de hidrólise, foram encontradas diferenças significativas (6,78 a 39,89\%) entre as marcas analisadas. Os resultados apontam para a necessidade e a importância da fiscalização contínua nos rótulos deste tipo de produto bem como a especificação obrigatória do grau de hidrólise em virtude das variações discrepantes apresentadas pelos produtos.
\end{abstract}

Palavras-chave: Suplementos Alimentares. Whey Protein. Hidrolisados de Proteínas. Rotulagem de Alimentos. Legislação Sobre Alimentos.

\begin{abstract}
In search of a better sports performance and body esthetics, consumers have spurred the growth of the food supplements market, mainly, the protein source in the intact and also hydrolyzed form. On the other hand, studies have shown nonconformities on the requirements regulated by current legislation regarding the labelling of these products, making quality analyses a topic of extreme importance. Thus, this study aimed at analyzing whey protein supplements regarding the presence of intact protein and the degree of hydrolysis, as well as their labeling adequacy assessment. For this, 9 brands of whey protein supplements available in the local market were analyzed. The protein content was evaluated by the Kjeldahl method and the degree of hydrolysis was determined by means of the relationship between $\alpha$-amino nitrogen and total nitrogen. For checking the labelling suitability a check list was prepared so as to comply with the current legislation. Among the assessed brands, it was observed that $88 \%$ of them presented at least one type of non-compliance concerning labelling. Regarding the protein content, a brand presented below (-35.08\%) the tolerance permitted by the legislation. In the verification of the degree of hydrolysis, significant differences were found (6.78 to 39.89\%) among the tested brands. The results point to the need and importance of continuous monitoring on the labels of this type of product as well as the mandatory specification of degree of hydrolysis due to the variations presented by the products.
\end{abstract}

Keywords: Food Supplements. Whey Protein. Protein Hydrolysates. Food Labeling. Food Legislation.

\section{Introdução}

Os suplementos nutricionais correspondem a produtos amplamente utilizados por atletas e praticantes de atividade física (FREITAS et al., 2015; BECKER et al., 2016). A demanda pela melhoria no rendimento esportivo e a melhora na estética corporal faz com que cada vez mais cresça o mercado destes produtos (SILVA et al., 2017). Além disso, o forte apelo do marketing populariza estes suplementos levando ao consumo indevido por milhares de pessoas conforme tem sido relatado em vários estudos epidemiológicos que demonstram cada vez mais o uso indiscriminado de produtos proteicos no Brasil (PEREIRA et al., 2009; COSTA et al., 2013; SILVA; SOUZA, 2016).
Dentre os suplementos proteicos mais vendidos no mercado, destacam-se aqueles formulados a partir das proteínas intactas ou hidrolisadas do soro do leite, conhecidos popularmente como whey protein, uma vez que apresentam alto valor nutricional e seu consumo está diretamente relacionado à hipertrofia muscular (CARRILHO, 2013). Além disso, as propriedades tecnológicas dessas proteínas as tornam um ingrediente muito utilizado pela indústria alimentícia em vários produtos como fórmulas infantis, bebidas, produtos cárneos e de padaria (SILVA, 2010). O processo de hidrólise destas proteínas tem sido utilizado visando a melhoria de suas propriedades nutricionais e funcionais, uma vez que o comprimento da cadeia desses peptídeos influencia diretamente 
sua velocidade e taxa de absorção (FRENHANI; BURINI, 1999; HINSBERGER; SANDHU, 2004), o que proporciona elevação da concentração de aminoácidos no plasma que, por outro lado, estimula a síntese de proteínas nos tecidos, elevando a taxa de hipertrofia muscular (HARAGUCHI et al., 2008).

Dessa forma, torna-se relevante caracterizar esses suplementos proteicos em relação à extensão da hidrólise proteica, a qual pode ser avaliada pelo método de grau de hidrólise que consiste em avaliar o percentual de ligações peptídicas clivadas em uma proteína (SILVA et al., 2009).

A Agência Nacional de Vigilância Sanitária (Anvisa) publicou a Resolução $N^{o} 18$ de 27 de abril de 2010, a qual dispõe sobre os requisitos de composição e de rotulagem dos alimentos para atletas. Desta maneira, a conformidade dos requisitos de rotulagem de suplementos proteicos comerciais consiste em uma ferramenta de comunicação de fundamental importância entre o fabricante e o consumidor, capaz de transmitir informações sobre um produto alimentício e subsidiar escolhas alimentares (MOREIRA et al., 2013). Estudos recentes têm demonstrado as não conformidades destes produtos disponibilizados no mercado, não cumprindo com requisitos regulamentados para esta classe de alimentos (INMETRO, 2014; LOVATO et al., 2014; OLIVEIRA et al., 2015).

Desta forma, o presente trabalho teve por objetivo caracterizar os suplementos proteicos do tipo whey protein em relação ao grau de hidrólise e avaliar a adequação da rotulagem em relação às legislações vigentes.

\section{Material e Métodos}

No ano de 2017 foram adquiridas 9 diferentes marcas de suplementos proteicos nacionais e importados do tipo whey protein, disponíveis no mercado nacional. Como critério de seleção, todos os produtos deveriam conter proteína hidrolisada em sua composição, sendo a fonte proteica proveniente somente do soro de leite. Após a coleta, as amostras foram mantidas em suas embalagens originais, em temperatura ambiente e protegidas da luz até o momento das análises, as quais foram realizadas dentro do prazo de validade.

\subsection{Análise de proteína}

O teor proteico das amostras investigadas foi quantificado pelo método de Kjeldahl, segundo procedimentos descritos na Association of Official Analytical Chemists (AOAC, 2016). Para isso, utilizou-se o fator de conversão de nitrogênio total para proteína de 6,38 .

\subsection{Grau de Hidrólise}

O grau de hidrólise foi avaliado segundo método descrito na AOAC (2016) por meio da relação entre o nitrogênio $\alpha$-aminado (NA), que foi determinado por meio da titulação com formol e o nitrogênio total (NT) conforme equação abaixo:

Equação 1: GH (\%) $=\frac{\text { nitrogênio } \alpha-\text { aminado (NA) }}{\text { nitrogênio total (NT) }} \times 100$

Para tal, $5 \mathrm{~mL}$ da amostra foi adicionada a um mesmo volume de solução de formaldeído-fenolftaleína. $\mathrm{O} \mathrm{pH}$ foi ajustado para 7,0 por meio de uma solução de $\mathrm{NaOH}$ a $0,2 \mathrm{~mol} \mathrm{~L}^{-1}$. Em seguida, a amostra foi titulada com essa mesma solução até a viragem de cor rósea, sendo, em seguida, adicionado um excesso, equivalente ao volume titulado, dessa mesma solução. Posteriormente, realizou-se uma retrotitulação com uma solução de $\mathrm{HCl}$ a $0,2 \mathrm{~mol} \mathrm{~L}^{-1}$. O NT foi quantificado conforme descrito anteriormente pelo método Kjeldahl.

\subsection{Avaliação da rotulagem}

A verificação da adequação da rotulagem das marcas de suplementos proteicos para atletas do tipo whey protein foi realizada de acordo com os requisitos estabelecidos nas Resoluções RDC ${ }^{\circ}{ }^{\circ} 259$, de 20 de setembro de 2002, RDC $n^{\circ} 360$, de 23 de dezembro de 2003, RDC no 359 , de 23 de dezembro de 2003, RDC n 18 de 27 de abril de 2010, RDC n ${ }^{\circ}$ 54 , de 12 de novembro de 2012, RDC n 26 de 02 de julho de 2015 e na Lei $n^{\circ} 10.674$ de 2003.

\subsection{Análise estatística}

Todas as análises foram realizadas em triplicata. Os dados foram submetidos à análise de variância por meio da ANOVA one way e para avaliação da comparação entre as médias do grau de hidrólise dos suplementos proteicos foi utilizado o Teste de Tukey $(\mathrm{p}<0,05)$.

\section{Resultados e Discussão}

No Quadro 1 estão apresentados para cada produto analisado, os teores de proteina conforme declarados nos rótulos (teor protéico rotulado), o valor determinado na análise laboratorial (teor protéico analisado), bem como o percentual de variação do teor analisado em relação ao rotulado.

Quadro 1 - Teor proteico total dos suplementos whey protein

\begin{tabular}{|c|c|c|c|}
\hline Produto & $\begin{array}{c}\text { Teor Proteico } \\
\text { Rotulado (\%) }\end{array}$ & $\begin{array}{c}\text { Teor Proteico } \\
\text { Analisado (\%) }\end{array}$ & Variação \\
\hline Controle & 86,67 & $72,07 \pm 1,07$ & $-16,84$ \\
\hline A & 73,53 & $74,24 \pm 0,16$ & $+0,96$ \\
\hline B & 75,00 & $74,36 \pm 0,36$ & $-0,85$ \\
\hline C & 75,00 & $73,55 \pm 0,37$ & $-1,93$ \\
\hline D & 73,33 & $68,91 \pm 0,64$ & $-6,02$ \\
\hline E & 50,91 & $33,05 \pm 0,05$ & $-35,08$ \\
\hline F & 93,33 & $87,27 \pm 0,20$ & $-6,49$ \\
\hline G & 83,87 & $77,19 \pm 0,43$ & $-7,96$ \\
\hline H & 64,00 & $64,96 \pm 0,79$ & $+1,50$ \\
\hline
\end{tabular}
Controle = proteína isolada do soro de leite intacta. Letras A, B, C, D, E, $\mathrm{F}, \mathrm{G}$ e H $=$ marcas analisadas. Variação com sinal positivo $(+)$ : o valor do teor protéico analisado foi superior ao valor rotulado; Variação com sinal negativo: (-): o valor do teor protéico analisado foi inferior ao valor rotulado.

Fonte: Dados da pesquisa. 
Segundo a Resolução RDC no 360 de 23 de dezembro de 2003, permite-se uma tolerância de $\pm 20 \%$ em relação aos valores declarados nos rótulos. Desta forma, observa-se no Quadro 1 que a maioria das marcas estavam de acordo com a legislação, exceto a marca E que apresentou uma variação de $-35,08 \%$ em relação ao valor declarado (BRASIL, 2003a).

Em um estudo realizado por Scarlato et al. (2016) ao avaliarem 15 marcas de whey protein, observou-se que 13\% destas apresentaram valores de proteínas inferiores ao limite estabelecido pela legislação. Oliveira et al. (2015) analisaram cinco marcas comerciais e observaram que $60 \%$ do teor proteico avaliado estava inferior ao rotulado. Este tipo de não conformidade causa prejuízos econômicos e nutricionais, já que o consumidor adquire um produto de elevado valor econômico e qualidade nutricional inferior ao esperado.

O grau de hidrólise do isolado (grupo controle) e dos hidrolisados proteicos de soro de leite de diferentes marcas está apresentado no Quadro 2.

Quadro 2 - Grau de hidrólise de isolado e hidrolisados proteicos de soro de leite

\begin{tabular}{|c|c|c|}
\hline Produto & $\begin{array}{c}\text { Composição do } \\
\text { Produto }\end{array}$ & $\begin{array}{c}\text { Grau de Hidrólise } \\
(\mathbf{\%})\end{array}$ \\
\hline Controle & $100 \%$ WPI & $6,50^{\mathrm{a}}$ \\
\hline A & WPC, WPI, WPH & $6,78^{\mathrm{a}}$ \\
\hline B & WPC, WPI, WPH & $7,40^{\mathrm{ab}}$ \\
\hline C & WPC, WPI, WPH & $7,51^{\mathrm{ab}}$ \\
\hline D & WPC, WPI, WPH & $8,75^{\text {bc }}$ \\
\hline E & WPC, WPI, WPH & $10,29^{\text {cd }}$ \\
\hline F & $100 \%$ WPH & $10,75^{\mathrm{d}}$ \\
\hline G & $100 \%$ WPH & $14,93^{\mathrm{e}}$ \\
\hline H & WPC, WPI, WPH & $39,89^{\mathrm{f}}$ \\
\hline \multicolumn{2}{|c|}{ Controle $=$ proteína isolada do soro de leite intacta. Letras A, B, C, E, }
\end{tabular}

Controle $=$ proteína isolada do soro de leite intacta. Letras A, B, C, D, E, $\mathrm{F}, \mathrm{G}$ e $\mathrm{H}=$ marcas analisadas.

Médias indicadas por letras iguais não diferem entre si a 5\% de significância na comparação de diferentes produtos. $\mathrm{WPC}=$ whey protein concentrado; $\mathrm{WPI}=$ whey protein isolado; $\mathrm{WPH}=$ whey protein hidrolisado .

Fonte: Dados da pesquisa.

Em relação a apresentação dos produtos, observa-se no Quadro 2 que seis das marcas analisadas, são uma mistura composta por 3 tipos de whey protein, chamados popularmente por "whey $3 W$ " (whey protein concentrado, whey protein isolado e whey protein hidrolisado), em proporções diferentes, de acordo com cada fabricante (marcas A, B, C, D, E e H).
Uma marca era composta apenas por whey protein isolado, a qual foi utilizada como amostra controle, já que o produto não passou pelo processo de hidrólise. Duas outras marcas eram compostas exclusivamente por whey protein hidrolisado (F e G).

Em relação ao grau de hidrólise, observa-se uma variabilidade $(6,78$ a $39,89 \%)$ entre os valores obtidos para as diferentes marcas comerciais. Nota-se que as marcas A, B e $\mathrm{C}$ apresentaram valores estatisticamente iguais ao controle. Deve ser ressaltado que a amostra controle refere-se a proteína intacta, ou seja, aquela que não foi submetida ao processo de hidrólise. Desta forma, esses produtos comercializados como hidrolisados correspondem, provavelmente a proteínas intactas, que estão sendo comercializadas com o apelo de serem hidrolisadas, lesando o consumidor, já que é um produto de maior preço e qualidade nutricional inferior. Por outro lado, os produtos D, E e F apresentaram valores maiores para o grau de hidrólise, diferindo estatisticamente dos primeiros. Já as marcas $\mathrm{G}$ e $\mathrm{H}$, apresentaram os valores mais elevados de $\mathrm{GH}$, $14,93 \%$ e $39,89 \%$, respectivamente, sendo que esse último apresentou valor muito superior com relação aos demais.

A legislação determina que os ingredientes sejam declarados no rótulo na ordem decrescente da quantidade adicionada. Porém, a proporção de proteína intacta e hidrolisada, bem como o grau de hidrólise da proteína não são obrigatórios na rotulagem. Desta forma, o consumidor pode ser prejudicado uma vez que não há informações suficientes no rótulo do produto adquirido, que não comunica sobre o grau de hidrólise e se realmente o mesmo contém proteína hidrolisada.

Além do grau de hidrólise, a análise do perfil peptídico dos suplementos proteicos permitiria uma visão mais completa das proporções e do tamanho das cadeias peptídicas e não somente o percentual de hidrólise proteica.

Ressalta-se, ainda, que não foram encontrados na literatura outros estudos que avaliaram o grau de hidrólise de suplementos proteicos tipo whey protein comerciais.

\subsection{Avaliação da rotulagem}

No Quadro 3 estão apresentados os requisitos de rotulagem avaliados para as diferentes marcas de suplementos proteicos tipo whey protein.

Quadro 3 - Check list da rotulagem para diferentes marcas de suplementos proteicos para atletas

\begin{tabular}{|c|c|c|c|c|c|c|c|c|c|c|}
\hline & & Controle & $\mathbf{A}$ & B & $\mathbf{C}$ & D & $\mathbf{E}$ & $\mathbf{F}$ & $\mathbf{G}$ & $\mathbf{H}$ \\
\hline \multirow{7}{*}{ 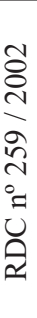 } & Denominação de venda do alimento & $\mathrm{C}$ & $\mathrm{C}$ & $\mathrm{C}$ & $\mathrm{C}$ & $\mathrm{C}$ & $\mathrm{C}$ & $\mathrm{C}$ & $\mathrm{C}$ & $\mathrm{C}$ \\
\hline & Lista de Ingredientes & $\mathrm{C}$ & $\mathrm{C}$ & $\mathrm{C}$ & $\mathrm{C}$ & $\mathrm{C}$ & $\mathrm{C}$ & $\mathrm{C}$ & $\mathrm{C}$ & $\mathrm{C}$ \\
\hline & Conteúdo líquido & $\mathrm{C}$ & $\mathrm{C}$ & $\mathrm{C}$ & $\mathrm{C}$ & $\mathrm{C}$ & $\mathrm{C}$ & $\mathrm{C}$ & $\mathrm{C}$ & $\mathrm{C}$ \\
\hline & Identificação da origem & $\mathrm{C}$ & $\mathrm{C}$ & $\mathrm{C}$ & $\mathrm{C}$ & $\mathrm{C}$ & $\mathrm{C}$ & $\mathrm{C}$ & $\mathrm{C}$ & $\mathrm{C}$ \\
\hline & $\begin{array}{l}\text { Nome ou razão social e endereço do importador } \\
\text { (produtos importados) }\end{array}$ & NA & $\mathrm{C}$ & NA & NA & $\mathrm{C}$ & NA & NA & NA & $\mathrm{C}$ \\
\hline & Identificação do lote & $\mathrm{C}$ & $\mathrm{C}$ & $\mathrm{C}$ & $\mathrm{C}$ & $\mathrm{C}$ & $\mathrm{C}$ & $\mathrm{C}$ & $\mathrm{C}$ & $\mathrm{C}$ \\
\hline & Declaração de aditivo ou $n^{\circ}$ INS & $\mathrm{C}$ & $\mathrm{C}$ & $\mathrm{C}$ & $\mathrm{C}$ & $\mathrm{C}$ & $\mathrm{C}$ & $\mathrm{C}$ & $\mathrm{C}$ & $\mathrm{C}$ \\
\hline
\end{tabular}




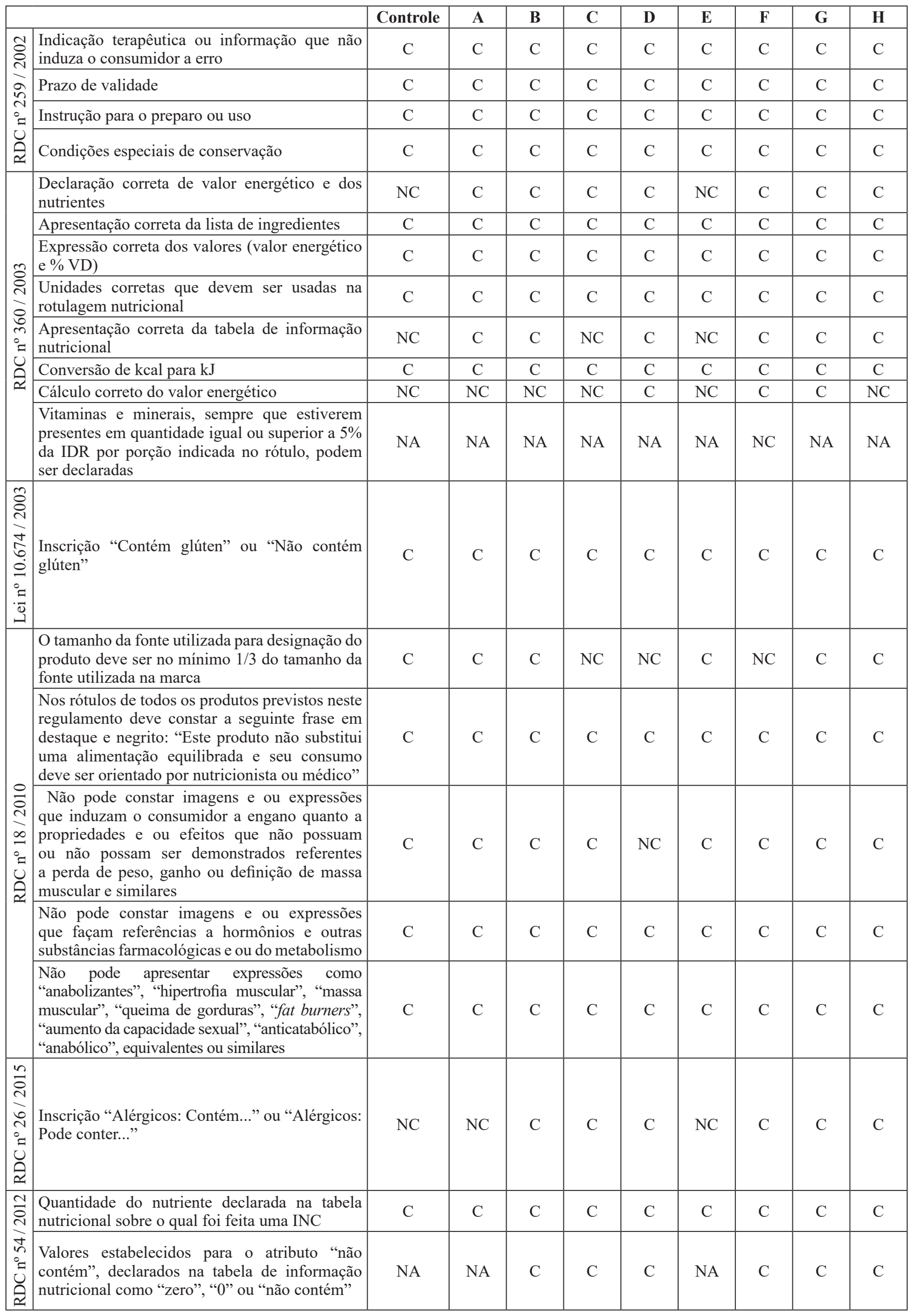




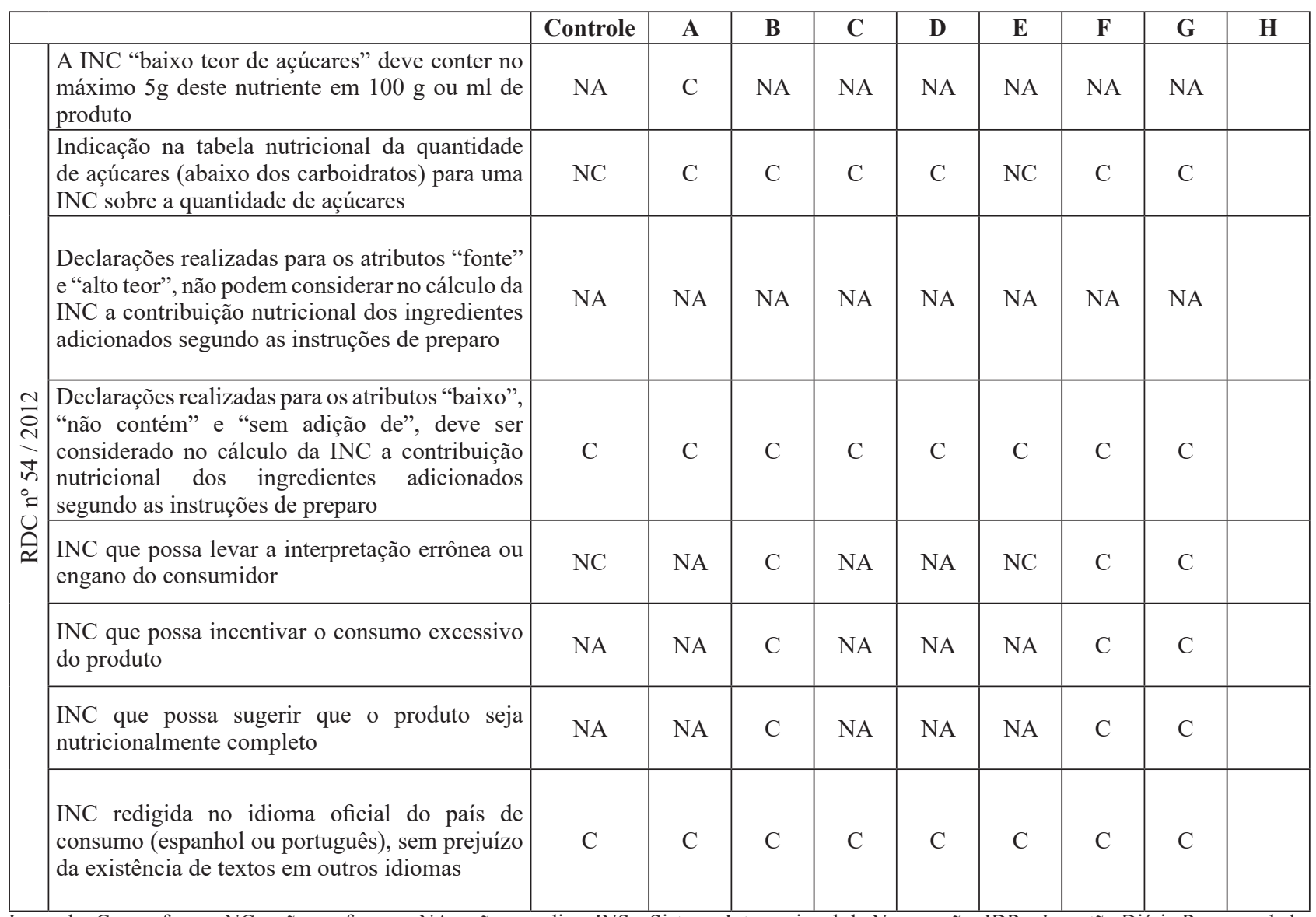

Legenda: C - conforme, NC - não-conforme e NA - não se aplica. INS - Sistema Internacional de Numeração; IDR - Ingestão Diária Recomendada; V.D. - Valores Diários; INC - Informação Nutricional Complementar.

Fonte: Dados da pesquisa.

Dentre as marcas avaliadas, ao considerar o check list acima, observa-se no cômputo geral que $88 \%$ das marcas apresentaram, no mínimo, um tipo de não conformidade.

Após analisar os rótulos segundo os requisitos estabelecidos pela Resolução RDC n ${ }^{\circ} 259$, de 20 de setembro de 2002, não foram constatadas irregularidades em nenhuma marca avaliada, ou seja, todos os produtos estavam de acordo com a legislação vigente (BRASIL, 2002).

Com relação aos requisitos estabelecidos pela Resolução RDC $\mathrm{n}^{\circ} 360$, de 23 de dezembro de 2003, 78\% (n=7) das marcas apresentaram não conformidades (Brasil, 2003a). Em $67 \%$ das marcas $(n=6)$ foi observado erros no cálculo do valor energético da porção. Em 33\% das marcas (marcas $\mathrm{C}, \mathrm{E}$ e controle) foram encontradas não conformidades na apresentação correta da tabela de informação nutricional, já que, os rótulos não apresentaram todos os nutrientes obrigatórios (valor energético, carboidratos, proteínas, gorduras totais, gorduras saturadas, gorduras trans, fibra alimentar e sódio) ou os mesmos estavam dispostos incorretamente de acordo com a legislação, já que a informação sobre a quantidade de açúcar deve constar em uma linha logo abaixo dos carboidratos e as marcas em questão dispuseram o açúcar como uma última linha da tabela. Observou-se, ainda, ao considerar o requisito que exige informar qual a medida caseira utilizada na porção, que essa informação estava especificada em 100\% dos rótulos, ou esteja, estava conforme. No entanto, torna-se importante destacar que em $78 \%(\mathrm{n}=7)$ dos produtos, percebeu-se que a medida caseira utilizada pelo fabricante corresponde ao medidor que acompanha o produto. Vale ressaltar que a RDC $n^{\circ} 359$, de 23 de dezembro de 2003, permite que pode ser declarada instrução específica, ou seja, utilização do medidor como forma de preparo, mas o consumidor pode ser prejudicado caso perca o dosador original do produto. Apenas $22 \%$ das marcas $(\mathrm{n}=2)$ apresentaram a colher de sopa como medida caseira alternativa, juntamente com o medidor original (BRASIL, 2003b).

Um estudo realizado pelo Inmetro (2014) para averiguação do atendimento dos rótulos dos suplementos proteicos do tipo whey protein, relatou que $73 \%$ das amostras não estavam em conformidade segundo critérios estabelecidos nas legislações vigentes. As principais não conformidades dizem respeito à expressão de valores com casas decimais. Apesar de não ser um problema que afete diretamente a saúde dos consumidores, sabe-se que a não utilização de uma casa decimal aumenta em dez vezes a incerteza dos resultados, sendo um elemento muito importante no entendimento das informações. Em outro trabalho realizado por Silva e Souza (2015) ao analisar 10 rótulos de suplementos proteicos nacionais e importados, foi 
observado que $100 \%$ dos produtos apresentaram, no mínimo, um tipo de não conformidade frente à legislação.

Com relação à Lei n ${ }^{\circ} 10.674$ de 2003, a qual determina que o produto deverá apresentar a inscrição "Contém Glúten" ou "Não Contém Glúten", $100 \%$ das amostras antederam à legislação (BRASIL, 2003c).

De acordo com as conformidades dos requisitos estabelecidos pela Resolução RDC n 18 de 27 de abril de 2010, notou-se que nenhum dos rótulos analisados apresentou imagens e ou expressões que fizessem referências a hormônios e outras substâncias farmacológicas e ou do metabolismo (BRASIL, 2010). Em 100\% dos produtos, a frase "Este produto não substitui uma alimentação equilibrada e seu consumo deve ser orientado por nutricionista ou médico", estava em destaque e em negrito, conforme a legislação. Os estudos de Moreira et al. (2013) e de Leite et al. (2015) demonstraram não conformidades neste item em 25 e $48 \%$, respectivamente.

Não foram encontradas irregularidades no requisito onde não se podem apresentar as expressões como "anabolizantes", "hipertrofia muscular", "massa muscular", "queima de gorduras", "fat burners", "aumento da capacidade sexual", "anticatabólico", "anabólico", equivalentes ou similares. Porém, observou-se que, apenas uma marca, apresentou imagem que pode induzir o consumidor ao engano quanto à propriedades e ou efeitos relacionados à perda de peso ou ganho de massa muscular. No estudo de Silva e Souza (2016) foi encontrada uma proporção de $20 \%$ em relação ao item anterior. Essas não conformidades podem transmitir ao consumidor a ideia errada de que o uso desses produtos seria suficiente para suprir as suas necessidades nutricionais e proporcionar efeitos ergogênicos.

Ainda em relação à RDC 18 de 27 de abril de 2010, foram encontradas irregularidades em 33\% (marcas C, D e F) dos rótulos no requisito onde determina que o tamanho da fonte utilizada para designação do produto deve ser no mínimo $1 / 3$ do tamanho da fonte utilizada na marca, não atendendo à RDC específica (BRASIL, 2010).

De acordo com a Resolução RDC 26 de 02 de Julho de 2015, ao avaliar o requisito referente à frase "Alérgicos: Contém (nomes comuns de alimentos que causam alergias alimentares)" ou "Alérgicos: Pode conter (nomes comuns de alimentos que causam alergias alimentares)" percebeu-se que em 44\% das amostras $(n=4)$ apresentaram não conformidade com a legislação vigente (BRASIL, 2015).

Observou-se, também que, em relação à Resolução RDC 54, de 12 de novembro de 2012, 22\% dos produtos analisados (marcas E e Controle) não estavam de acordo com a legislação. Ambos os produtos contêm em sua embalagem frase que faz menção em conter um aminoácido o qual já faz parte naturalmente da proteína do soro do leite, podendo levar o consumidor a uma interpretação errônea sobre adição complementar deste aminoácido ao produto (BRASIL, 2012).

\section{Conclusão}

O teor proteico dos suplementos comerciais estava de acordo com o valor declarado, exceto para a marca. E, que apresentou uma variação de $-35,08 \%$, sendo a única marca reprovada neste parâmetro. Em relação ao grau de hidrólise, foi encontrado valores com diferenças significativas entre as marcas analisadas, sugerindo a necessidade da obrigatoriedade da informação sobre o grau de hidrólise no rótulo. A análise da rotulagem dos produtos demonstrou que $88 \%$ dos suplementos proteicos analisados apresentaram algum tipo de não conformidade frente à legislação. A fiscalização contínua de suplementos proteicos consiste em uma forma de garantir que os consumidores tenham acesso a produtos adequados e informações declaradas fidedignas.

\section{Referências}

AOAC (Association of Official Analytical Chemistry). Official methods of analysis. Maryland: AOAC, 2016.

BECKER, L.K. et al. Efeitos da suplementação nutricional sobre a composição corporal e o desempenho de atletas: uma revisão. Rev. Bras. Nutr. Esportiva, v.10, n.55, p.93-111, 2016.

BRASIL. Ministério da Saúde. Secretaria de Vigilância Sanitária. Resolução da Diretoria Colegiada - RDC N²6, de 2 de julho de 2015. Dispõe sobre os requisitos para rotulagem obrigatória dos principais alimentos que causam alergias alimentares. Diário Oficial da União. Brasília, 2015.

BRASIL. Agência Nacional de Vigilância Sanitária. Resolução (RDC) $\mathrm{n}^{\circ} 18$, de 27 de abril de 2010. Aprova o Regulamento Técnico sobre Alimentos para Atletas. Diário Oficial da União. Brasília, 2010.

BRASIL. Ministério da Saúde. Secretaria de Vigilância Sanitária. Resolução (RDC) $n^{\circ}$ 259, de 20 de setembro de 2002. Aprova o Regulamento Técnico sobre Rotulagem de Alimentos Embalados. Diário Oficial da União. Brasília, 2002.

BRASIL. Ministério da Saúde. Secretaria de Vigilância Sanitária. Resolução (RDC) no 359, de 23 de dezembro de 2003. Aprova Regulamento Técnico de Porções de Alimentos Embalados para Fins de Rotulagem Nutricional. Diário Oficial da União. Brasília, 2003 b.

BRASIL. Ministério da Saúde. Secretaria de Vigilância Sanitária. Resolução (RDC) no 360, de 23 de dezembro de 2003. Aprova Regulamento Técnico sobre Rotulagem Nutricional de Alimentos Embalados, tornando obrigatória a rotulagem nutricional. Diário Oficial da União. Brasília, 2003a.

BRASIL. Ministério da Saúde. Secretaria de Vigilância Sanitária. Resolução (RDC) $n^{\circ} 54$, de 12 de novembro de 2012. Dispõe sobre Regulamento Técnico sobre Informação Nutricional Complementar. Diário Oficial da União. Brasília, 2012.

BRASIL. Presidência da República. Lei no 10.674 , de 16 de maio de 2003. Obriga a que os produtos alimentícios comercializados informem sobre a presença de glúten, como medida preventiva e de controle da doença celíaca. Brasília, 2003c.

CARRILHO, L.H. Benefícios da utilização da proteína do soro de leite whey protein. Rev. Bras. Nutr. Esportiva, v.7, n.40, p.195203, 2013.

COSTA, D.C.; ROCHA, N.C.A.; QUINTÃO, D.F. Prevalência do uso de suplementos alimentares entre praticantes de atividade física em academias de duas cidades do Vale do Aço - MG: fatores associados. Rev. Bras. Nutr. Esportiva, v.7, n.41, p.287- 
$299,2013$.

FREITAS, H.R. et al. Avaliação da rotulagem e informação nutricional de suplementos proteicos importados no Brasil. Rev. Bras. Nutr. Esportiva, v.9, n.49, p.14-24, 2015.

FRENHANI, P.B.; BURINI, R.C. Mechanisms of absorption of amino acids and oligopeptides: control and implications in human diet therapy. Arq. Gastroenterol., v.36, n.4, p.227-237, 1999. doi: 10.1590/s0004-28031999000400011

HARAGUCHI, F. K.; ABREU, W. C.; PAULA, H. Proteínas do soro do leite: composição, propriedades nutricionais, aplicações no esporte e benefícios para a saúde humana. Rev. Nutr., v.4, n.19, p.479-488, 2008. doi: 10.1590/S1415-52732006000400007

HINSBERGER, A.; SANDHU, B.K. Digestion and absorption. Curr. Paediatr., v.14, p.605-611, 2004. doi: 10.4322/ nutrire.2013.026

INMETRO - Instituto Nacional de Metrologia, Qualidade e Tecnologia. Programa de análise de produtos: relatório final sobre a análise em suplementos proteicos para atletas - whey protein. 2014. Disponível em: <http://www.inmetro.gov.br/consumidor/ produtos/Relatorio_Whey_Final.pdf $>$ Acesso em: 18 out. 2020.

LEITE, V.C.C. et al. Análise dos rótulos de suplementos proteicos para atletas, segundo as normas brasileiras em vigência. Cad. UniFOA, n.28, p.69-74, 2015.

LOVATO, F. et al. Avaliação da conformidade de suplementos alimentares frente à legislação vigente. Rev. Bras. Nutr. Esportiva, v.8, n.47, p.330-335, 2014.
MOREIRA, S.S.P. et al. Avaliação da adequação da rotulagem de suplementos esportivos. Rev. Corpus Scie., v.9, n.2, p.45-55, 2013.

OLIVEIRA, L.C.B.P. et al. Análise centesimal e comparativa de suplementos de proteínas do soro do leito bovino: whey protein. Rev. Bras. Nutr. Esportiva, v.9. n.51, p.223-223, 2015.

PEREIRA, C.V. et al. Perfil do uso de whey protein nas academias de Curitiba-PR. Rev. Bras. Nutr. Esportiva, v.3, n.17, p.423-431, 2009.

SCARLATO, R.C. et al. Determinação do teor de proteínas e carboidratos totais em suplementos do tipo Whey Protein. Rev. Inst. Adolfo Lutz, v.75, p. 1-7, 2016.

SILVA, L.V.; SOUZA, S.V.C. Qualidade de suplementos proteicos: avaliação da composição e rotulagem. Rev. Instituto Adolfo Lutz, v.75, p.1-17, 2016.

SILVA, M.C. et al. Grau de hidrólise e perfil peptídico de hidrolisados enzimáticos obtidos a partir de concentrado proteico do soro de leite. Aliment. Nutr., v.20, n.3, p.395-402, 2009.

SILVA, M.R. Concentrado proteico do soro de leite com alto teor de oligopeptídeos e elevada atividade inibitória sobre a enzima conversora de angiotensina. Belo Horizonte: UFMG, 2010.

SILVA, R.O; BARROS, D.F.; GOUVEIA, T.M.O.A. Eu tenho a força! A popularização do consumo de suplementos alimentares e a vulnerabilidade do consumidor. Rev. ADM., v.21, n.1, p.34-50, 2017. doi: $10.21714 / 2237-51392017 \mathrm{v} 21 \mathrm{n} 1 \mathrm{p} 034050$. 